\title{
Abatement of the clostridial load in the teats of lactating cows with lysozyme derived from donkey milk
}

\author{
F. Adduci, ${ }^{1}$ H. S. Elshafie, ${ }^{1}$ C. Labella, ${ }^{1}$ M. Musto, ${ }^{1}$ P. Freschi, ${ }^{1}$ R. Paolino,${ }^{1 *}$ M. Ragni, ${ }^{2}$ and C. Cosentino ${ }^{1}$ \\ ${ }^{1}$ School of Agricultural, Forestry, Food, and Environmental Sciences, University of Basilicata, 85100 Potenza, Italy \\ ${ }^{2}$ Department of Agro-Environmental and Territorial Sciences, University of Bari Aldo Moro, 70126 Bari, Italy
}

\section{ABSTRACT}

The use of a sterilized product for washing cows' udders before milking may be useful to reduce or prevent Clostridium tyrobutyricum contamination, the main cause of the late-blowing defect in hard and semi-hard cheeses. The aim of this research was to evaluate the antibacterial efficacy of an experimental formula containing $15 \%$ condensed donkey milk (lysozyme content $825 \mathrm{mg} / \mathrm{L}$ ). The antimicrobial activity of condensed milk was first evaluated in vitro, using the disk diffusion method, on the following microorganisms: Bacillus megaterium, Bacillus mojavensis, Clavibacter michiganensis, and Clostridium tyrobutyricum. These results were compared with the effects of 2 antibiotics, ampicillin $(100 \mathrm{mg} / \mathrm{mL})$ and kanamycin $(50 \mathrm{mg} / \mathrm{mL})$, and a commercial pre-dipping formula. The results showed that the inhibitory activity of lysozyme from donkey milk on all the considered microorganisms was higher than that of the commercial product and similar to that of the 2 antibiotics. Next, the formula with lysozyme was compared with a commercial pre-dipping formula on 48 lactating cows (24 cows in each group). Skin tests were performed on teats before and after pre-dipping. Results showed that the formula with condensed milk significantly reduced the clostridial load detected on the skin of cows' teats before cleaning $(-55.61 \%$ vs. $-27.99 \%$ ) and in the bulk milk of the experimental group compared with the control group with commercial product $(-52.53 \%$ vs. $-32.42 \%)$.

Key words: Clostridium tyrobutyricum, pre-dipping, lysozyme, donkey milk, late blowing

\section{INTRODUCTION}

Different categories of environmental microorganisms, although nonpathogenic, have a strong anti-dairy activity, causing the late-blowing defect in cheese.

Received January 16, 2019.

Accepted March 6, 2019.

*Corresponding author: rosanna.paolino@unibas.it
Among these, species of the genus Clostridium (hereafter, clostridia) play an important role in degradation of organic substances in all types of soil by producing acids, alcohols, $\mathrm{CO}_{2}$, and $\mathrm{H}_{2}$. Clostridia spores may be released from the ground onto animal fodder through environmental factors such as rain or wind, as well as through the actions of machinery. The spores thus enter the mangers of dairy cows and, once swallowed, pass unaltered into the digestive tract, where vegetative cells sporulate. This explains the significant increase in the number of spores between ingestion (ration) and excretion (stools). Milk in the healthy udder is sterile, but it becomes contaminated by the microorganisms present in the environment during milking. Such microorganisms are ubiquitous, and contamination can occur during or between milkings, when animals feed or ruminate (Colombari et al., 1999; Kalač, 2011). However, most contamination occurs immediately after milking, when the keratin cap has not yet formed and the sphincter of the teat is still open (Stadhousers and Jørgensen, 1990). During milking, the number of spores in the milk varies due to different udder-cleaning operations (Benkerroum, 2008; Garde et al., 2011). In the milk, spores remain viable throughout all stages of cheese production (Cosentino et al., 2018), and the heating to which the curd is subjected cannot inactivate them. During the ripening period of cheese, while potentially pathogenic germs decrease (Stadhousers and Jørgensen, 1990), clostridia find an environment conducive to their multiplication, resulting in the late-blowing defect (Bottazzi, 1993; Panari et al., 2001). This defect manifests mainly in the disorder of pasta filata cheese to create a spongy consistency, or in cracking and forming cavernous openings that particularly affect the central part, tending to make the cheese swell (Cosentino et al., 2013). If marked, the defect can give rise to rancid flavors and unpleasant smells due to the production of butyric acid and acetic aldehyde, irreparably destroying the commercial value of the product (Cosentino et al., 2015a,b). Clostridia bacteria are most frequently responsible for the late-blowing defect, particularly Clostridium tyrobutyricum, a gram-positive species that 
ferments lactates, giving rise to butyric acid, carbon dioxide, and hydrogen (Garde et al., 2011).

With appropriate management of the milk production chain, the number of clostridia spores can be considerably reduced, improving the quality of dairy products. In fact, the number of spores in most commercial cheeses, such as Grana Padano, has been greatly reduced recently (Niro et al., 2017), thus far remaining below the regulatory limit of 200 spores/L. In most dairies, lysozyme E1105 extracted from egg whites is used to prevent the late-blowing defect (Cosentino et al., 2015a,c). An important and alternative source of lysozyme is donkey milk. As reported by Zhang et al. (2008), the lysozyme content of donkey milk (1.0 to 3.7 $\mathrm{mg} / \mathrm{mL})$ is higher than that of cow milk $(0.09 \mathrm{mg} / \mathrm{L})$. Cow milk has been tested on various microorganisms, as reported by van Hooijdonk et al. (2000) and Cosentino et al. (2018), and the antibacterial activity of donkey milk has been tested on different microorganisms (Šarić et al., 2014; Cosentino et al., 2016b; Koutb et al., 2016).

Ávila et al. (2014) reported the inhibitory effects of lysozyme on certain strains of $C$. tyrobutyricum, Clostridium butyricum, and Clostridium beijerinckii, whereas no inhibitory effect was recorded for Clostridium sporogenes. Conte et al. (2012) evaluated the inhibitory activity of lysozyme against Pseudomonas spp., and partially on some strains of Salmonella, although no inhibition was observed for Staphylococcus aureus, Escherichia coli, or Klebsiella pneumoniae. Zhang et al. (2008) reported high antibacterial activity of donkey milk against Salmonella choleraesuis and Shigella dysenteriae. Moreover, previous studies by Cosentino and colleagues (2013, 2015a,b, 2016a) showed that donkey lysozyme can be successfully used to lower the growth of the bacteria responsible for late blowing in cheese. Hence, donkey milk could be used as an important inhibitor for late blowing, acting as a suitable substitute for egg lysozyme.

In this study, the antibacterial activity of condensed donkey milk was evaluated in an in vitro test against clostridia and in vivo on the skin of teats of lactating cows during the pre-dipping phase in the milking parlor.

\section{MATERIALS AND METHODS}

In this trial, donkey milk was pasteurized and successively condensed. Pasteurization was performed by heating raw donkey milk to $63^{\circ} \mathrm{C}$ for $30 \mathrm{~min}$. Afterward, to obtain physical stability, the pasteurized milk was condensed via rotary evaporator (RV8, Kettenbach GmbH \& Co. KG, Eschenburg, Germany) under the following conditions: water bath temperature $35^{\circ} \mathrm{C}$; pressure 4,000 $\mathrm{Pa}$; processing time 2 and $3 \mathrm{~h}$ for condensation at 20 and $40 \%$, respectively (i.e., 80 and $60 \%$ of water was removed, respectively). To extract and quantify lysozyme in condensed donkey milk, we used the method proposed by Labella et al. (2016). Lysozyme extraction was performed using $\mathrm{NaCl}$ solution (1 $\mathrm{mol} / \mathrm{L}$ ). After stirring and filtration, the sample was analyzed using HPLC-UV (280 nm).

\section{In Vitro Evaluation}

We performed antibacterial testing of the donkey milk using the disk diffusion method as reported by Bhunia et al. (1988) and Elshafie et al. (2016a). Briefly, the disc diffusion assay was carried out by inoculating $15 \mathrm{~mL}$ of each treatment over the blank discs $(6 \mathrm{~mm}$; Oxoid, Basingstoke, UK). Antibacterial activity was evaluated by measuring the diameter of inhibition zones $(\mathrm{mm})$. We selected representative bacterial strains to evaluate the antibacterial activity of the pre-dipping preparation containing donkey milk lysozyme (lysozyme predipping, LP). The tested bacteria included 4 gram-positive strains (Bacillus megaterium, Bacillus mojavensis, Clavibacter michiganensis, and C. tyrobutyricum) and 1 gram-negative strain, E. coli. Bacteria were cultured on King's B medium (Sigma-Aldrich, Milan, Italy), except E. coli, which was cultured in Luria-Bertani medium (Sigma-Aldrich), as specified by Elshafie et al. (2016b). All bacterial cultures were incubated at $30 \pm$ $2^{\circ} \mathrm{C}$ for $48 \mathrm{~h}$. We used $20 \%$ condensed milk in the test, as this showed the best physical stability. The LP solution contained $15 \%$ condensed donkey milk (lysozyme content $825 \mathrm{mg} / \mathrm{L}$ ), water, glycerol, lauryl glucoside, sodium lauryl sarcosine, benzyl alcohol, sodium dehydroacetate, citric acid, sodium benzoate, and potassium sorbate. As reported by Cosentino et al. (2016b) and Labella et al. (2016), the condensation process does not affect the antioxidant activity or the lysozyme content in donkey milk. We compared LP with 2 common antibiotics - ampicillin (100 $\mu \mathrm{g} / \mathrm{mL})$ and kanamycin $(50 \mu \mathrm{g} / \mathrm{mL})$ - and a commercial pre-dipping solution (CP). The composition of CP was $1 \%$ phosphoric acid, perfume, anionic surfactant (fatty alcohol ethoxysulfate), hydrogen peroxide, $1 \%$ urea, nonionic surfactants (alkylpolyglucoside, esterified fatty acid), panthenol, sorbitol, lactic acid, and 5\% glycerol.

\section{In Vivo Evaluation of Pre-dipping Preparations}

Pre-dipping preparations LP and CP were tested by skin tests once per week for $4 \mathrm{mo}$ on the teats of 48 lactating multiparous Italian Friesian cows (24 cows in each group), on a farm located in northwestern Basilicata, Italy. The cows had an average live weight of 
$646 \mathrm{~kg}$ at the beginning of the study. The livestock system on this farm is freestall housing with a rest area in stalls. Before applying pre-dipping, an initial skin test was performed on the teats to evaluate the pretreatment bacterial load; then the bacterial load after treatment was determined. Skin tests were carried out using sterile swabs moistened with saline $0.08 \%$ on all 4 teats in the area within $3 \mathrm{~cm}$ from the papillary orifice. Pre-dipping solutions LP and CP were each applied using spray dispensers (20 $\mathrm{mL}$ per item) and were allowed to sit on the udders for $3 \mathrm{~min}$. Then, the udders were washed and dried with paper, and the skin test was repeated. After milking, bulk milk samples were taken from each group to assess clostridia count.

\section{Clostridia Count in Bulk Milk}

We evaluated the most probable number (MPN) of clostridia in the bulk milk of each group according to the following method. Ten milliliters of Bryant Burkey broth base with the blue dye resazurin (Sigma-Aldrich) was dispensed into glass vials that had been previously sterilized at $121^{\circ} \mathrm{C}$ for $15 \mathrm{~min}$. To each vial was added 1 $\mathrm{mL}$ of milk from the sample along with $2 \mathrm{~mL}$ of paraffin (that had been previously sterilized at $121^{\circ} \mathrm{C}$ for 15 min) at $58 \pm 2^{\circ} \mathrm{C}$. Each inoculated tube was heated at $75^{\circ} \mathrm{C}$ for $15 \mathrm{~min}$ to eliminate vegetative spores. All tubes were incubated at $37^{\circ} \mathrm{C}$ for $7 \mathrm{~d}$, after which time the number of spores was determined. At the end of the incubation time, displacement of the paraffin plug indicated gas production related to the presence of clos- tridia. Clostridia were only enumerated in those tubes showing positive gas production, and the number of clostridia fermenting the lactate in each 1-mL sample was determined $(\mathrm{MPN} / \mathrm{mL})$.

\section{Statistical Analysis}

Means were analyzed using Statistical Package for the Social Sciences software (SPSS, version 13.0, 2004; Chicago, IL), and we used the Tukey post hoc test to detect significant differences among the different treatments at $P<0.05$.

\section{RESULTS AND DISCUSSION}

\section{In Vitro Evaluations}

We detected no significant differences between the inhibitory efficacy of LP and the 2 antibiotics against Clavibacter michiganensis. For the other bacterial species, ampicillin and kanamycin had a significantly greater inhibitory effect than LP $(P<0.05$; Figure 1$)$. Regarding the bioactivity against $B$. megaterium and C. michiganensis, LP showed the highest inhibition effect compared with the other treatments. The highest inhibition against B. mojavensis and C. tyrobutyricum was observed in the case of ampicillin followed by LP (Figure 2).

The inhibitory activity recorded for LP was largely due to the action of the donkey milk lysozyme against the gram-positive microorganisms for which we tested. $\square$ B. megaterium
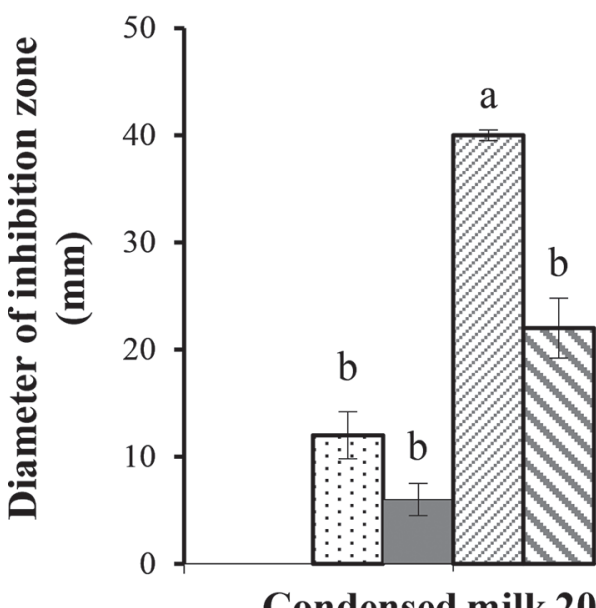

Condensed milk 20\% $\square$ B. mojavensis

๑Clav. michiganensis

๑Clos. tyrobutyricum

Figure 1. In vitro antibacterial activity of condensed donkey milk compared with ampicillin and kanamycin in a disk diffusion assay. Bars with different letters (a, b) for each tested bacteria (Bacillus megaterium, Bacillus mojavensis, Clavibacter michiganensis, and Clostridium

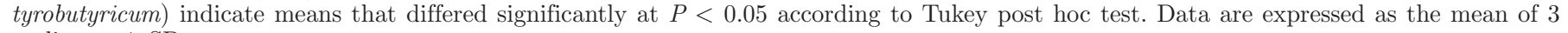
replicates $\pm \mathrm{SD}$. 


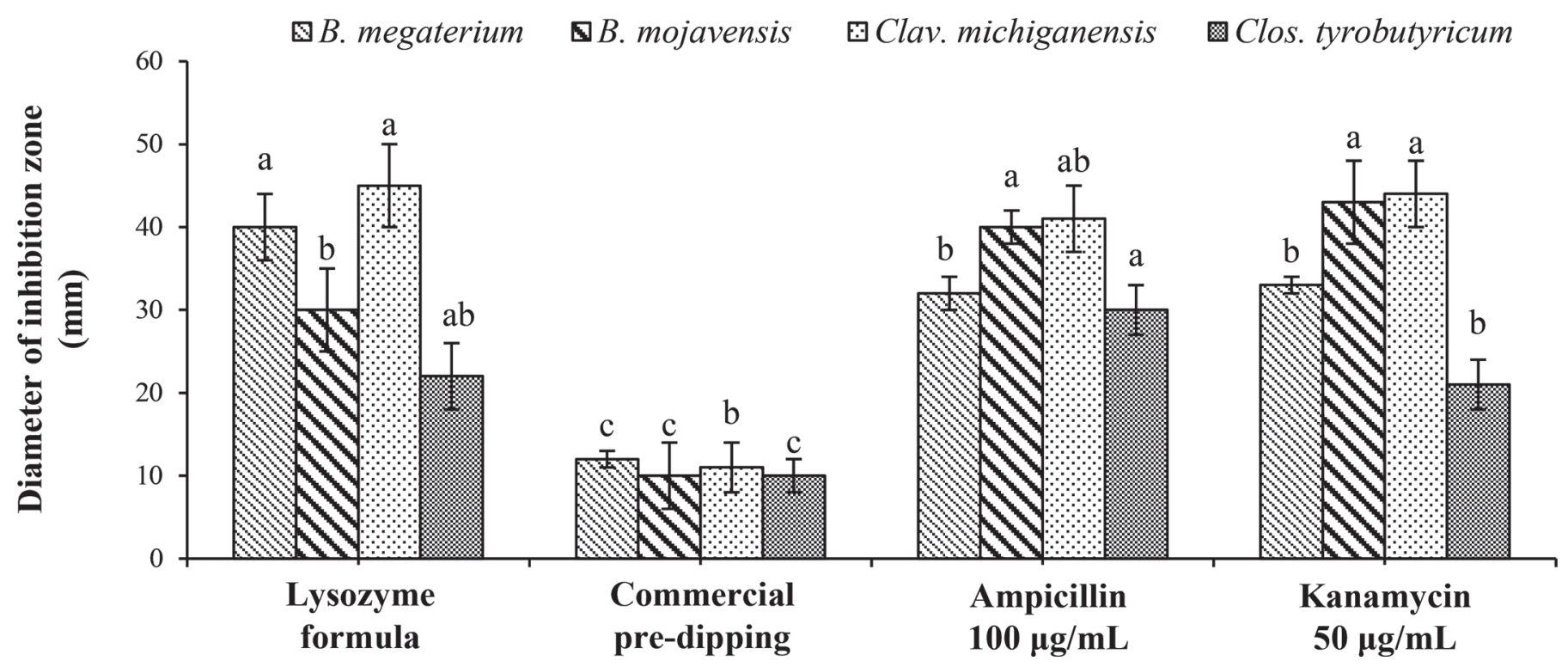

Figure 2. In vitro antibacterial activity of lysozyme formulation compared with a commercial pre-dip, ampicillin, and kanamycin. Bars with different letters (a-c) for each tested bacteria (Bacillus megaterium, Bacillus mojavensis, Clavibacter michiganensis, and Clostridium tyrobutyricum) indicate means that differed significantly at $P<0.05$ according to Tukey post hoc test. Bars with different letters (a-c) indicate means that differed significantly at $P<0.05$ for each tested bacteria (Bacillus megaterium, Bacillus mojavensis, Clavibacter michiganensis, and Clostridium tyrobutyricum) according to Tukey post hoc test. Data are expressed as the mean of 3 replicates \pm SD.

Lysozyme is a glycoside hydrolase that enhances the hydrolysis of 1,4- $\beta$ linkages between $N$-acetylmuramic acid and $N$-acetyl-D-glucosamine residues in peptidoglycan, the major component of gram-positive bacterial cell walls (Manchenko, 1994). This activity is carried out synergistically with lactoferrin and immunoglobulins contained in milk (Benkerroum, 2008).

The inhibitory efficacy of LP was highest against $B$. megaterium (Figure 2). The efficacy of both tested antibiotics against $B$. mojavensis was significantly higher than that of LP, and that of LP was higher than that of the commercial formula. The highest significant activity against Clavibacter michiganensis was observed with LP and the antibiotics, and the lowest significant activity was observed with $\mathrm{CP}(P<0.05)$.

\section{In Vivo Evaluations}

Results of the in vivo trial for antibacterial efficacy of the condensed donkey milk pre-dipping formula against

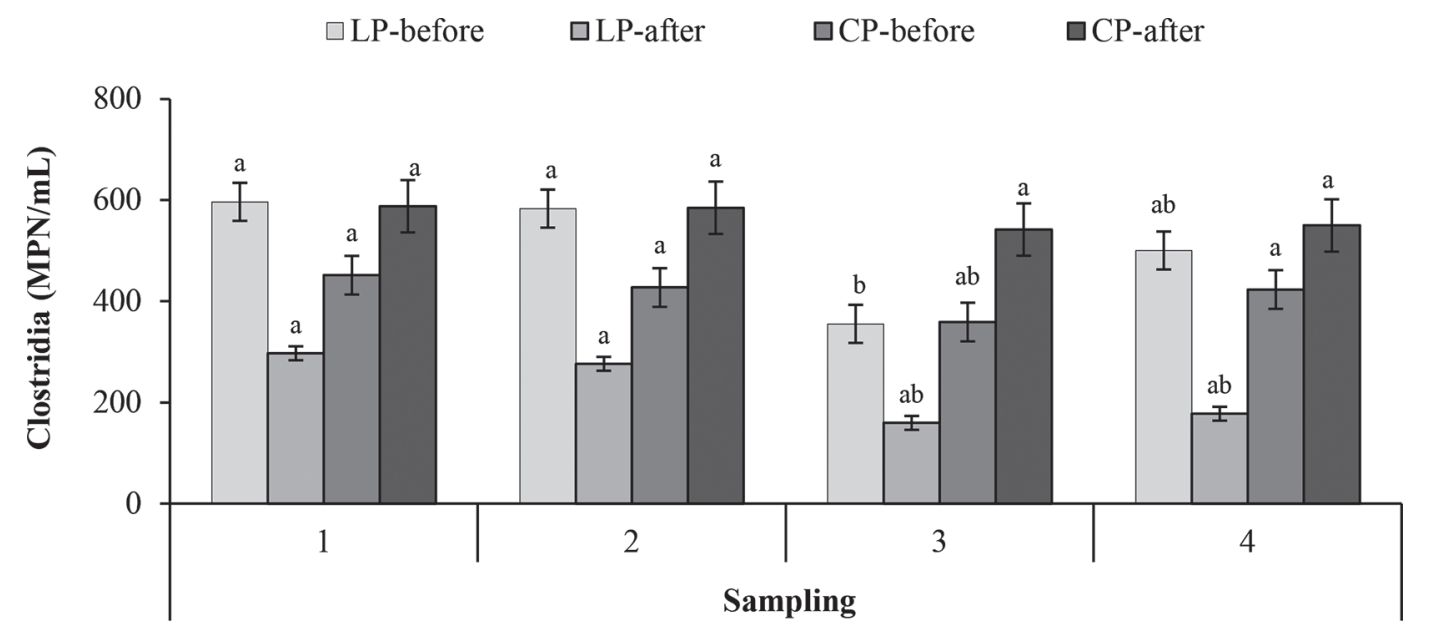

Figure 3. Clostridia contamination [most probable number (MPN)/mL] of cows' teat skin before and after pre-dipping treatment with lysozyme pre-dip (LP) and commercial pre-dip (CP). Bars with different letters (a, b) indicate differences in means across 4 sampling times within each treatment $(P<0.05)$ according to Tukey post hoc test. Data are expressed as the mean of 3 replicates \pm SD. 


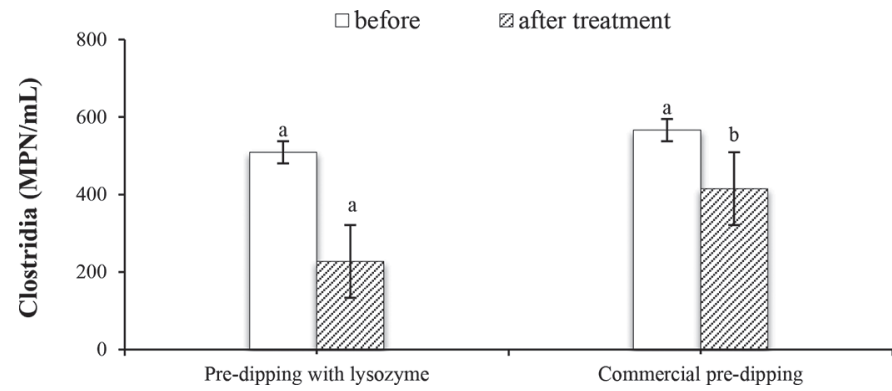

Figure 4. Overall mean clostridia contamination [most probable number $(\mathrm{MPN}) / \mathrm{mL}$ ] of cows' teat skin before and after pre-dipping treatment lysozyme pre-dip or commercial pre-dip. Bars with different letters $(\mathrm{a}, \mathrm{b})$ for each treatment indicate means that differed significantly at $P<0.05$ according to Tukey post hoc test.

lactate-fermenting clostridia confirmed the in vitro results (Figure 3). Regarding the effect of pre-dipping treatment against clostridia contamination, LP showed the highest inhibition effect after application during the third and fourth months compared with CP treatment. The clostridia load on teats treated with LP $(227$ vs. $415 \mathrm{MPN} / \mathrm{mL})$ was significantly $(P<0.05)$ lower than that of the CP treatment (Figure 4). Clostridia contamination in milk was $53.53 \%$ lower than teat skin contamination after treatment application for the LP group. Clostridia contamination in milk after washing with CP was $32.42 \%$ lower than teat skin contamination (Figure 5). These data showed that the experimental formula has more inhibitory capacity even in bulk milk (post-milking).

\section{CONCLUSIONS}

Adding donkey milk to a formula for pre-dipping led to positive results in udder-cleaning operations. In

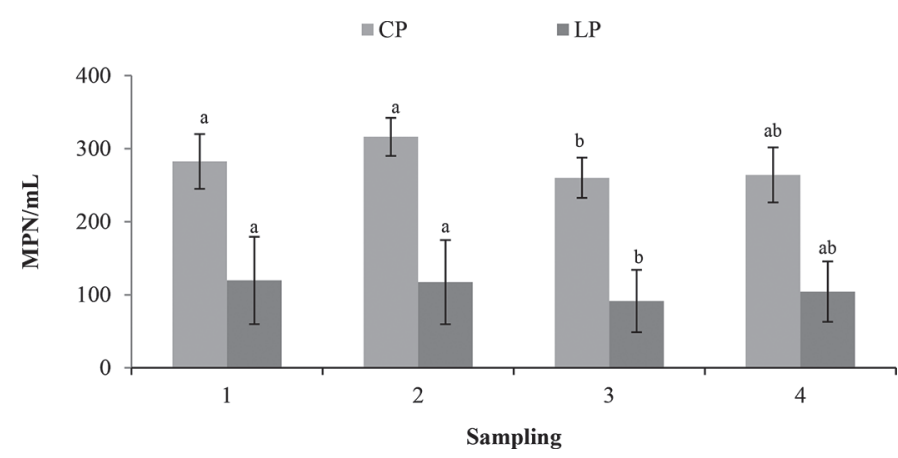

Figure 5. Clostridia contamination [most probable number $(\mathrm{MPN}) / \mathrm{mL}$ ] of bulk milk in post-milking after application of the commercial pre-dip (CP) and lysozyme pre-dip (LP) treatments. Bars with different letters for each group indicate means were significantly different at $P<0.05$ according to Tukey post hoc test. Data are expressed as the mean of 3 replicates \pm SD. particular, the lysozyme in our experimental formula can be used to decrease the growth of bacteria responsible for late blowing in cheese. The inhibitory activity recorded for the formula was largely due to the action of the donkey milk lysozyme against the tested grampositive microorganisms. Moreover, in the pre-dipping phase in the milking parlor, the experimental donkey milk formula exhibited more detergency and inhibitory capacity than a commercial pre-dipping solution. Overall, these results mark an important step toward new formulas for udder-cleaning operations, to reduce the number of bacteria in milk and the number of clostridia spores, thus improving dairy quality.

\section{ACKNOWLEDGMENTS}

This research was supported by Basilicata Region Rural Development Programme 2014-2020, Measure 16 - Cooperation, Sub-measure 16.1. INNOPROLATTE Project "Application of process and product innovations for the development of the milk supply chain in Basilicata" (Potenza, Italy).

\section{REFERENCES}

Ávila, M., N. Gómez, T. Hernández, and S. Garde. 2014. Inhibitory activity of reuterin, nisin, lysozyme and nitrite against vegetative cells and spores of dairy-related Clostridium species. Inter. J. Food Microbiol. 172:70-75. https://doi.org/10.1016/j.ijfoodmicro.2013 .12 .002 .

Benkerroum, N. 2008. Antimicrobial activity of lysozyme with special relevance to milk. Afr. J. Biotechnol. 7:4856-4867.

Bhunia, A. K., M. C. Johnson, and B. Ray. 1988. Purification, characterization and antimicrobial spectrum of a bacteriocin produced by Pediococcus acidilactici. J. Appl. Bacteriol. 65:261-268.

Bottazzi, V. 1993. I batteri lattici nella maturazione del formaggio grana. Ind. Latte 29:73-88.

Colombari, G., G. Borreani, and G. M. Crovetto. 1999. Comparison of lucerne silage and ventilated hay in maize silage-based rations for dairy cows for the production of milk destined for Grana cheese. Grass Forage Sci. 54:184-194.

Conte, F., M. Foti, M. Malvisi, C. Giacopello, and R. Piccinino. 2012. Assessment of antibacterial activity of donkey milk lysozyme. Safety and hygiene issues. Large Anim. Rev. 18:13-16.

Cosentino, C., H. S. Elshafie, C. Labella, C. D'Adamo, P. Pecora, M. Musto, R. Paolino, I. Camele, and P. Freschi. 2018. Study the protective effect of an innovative product based-cow milk against some human skin-bacterial pathogens. J. Biol. Res. (Thessalon.) 91:35-39.

Cosentino, C., D. Faraone, R. Paolino, P. Freschi, and M. Musto. 2016a. Sensory profile and acceptability of a cow milk cheese manufactured by adding jenny milk. J. Dairy Sci. 99:228-233. https:// doi.org/10.3168/jds.2015-10107.

Cosentino, C., C. Labella, H. S. Elshafie, I. Camele, M. Musto, R. Paolino, C. D'Adamo, and P. Freschi. 2016b. Effects of different heat treatments on lysozyme quantity and antimicrobial activity of jenny milk. J. Dairy Sci. 99:5173-5179. https://doi.org/10.3168/ jds.2015-10702.

Cosentino, C., C. Labella, M. Musto, R. Paolino, S. Naturali, and P. Freschi. 2015c. Effect of different physical treatments on antioxidant activity of jenny milk. Int. J. Agric. Sci. 5:874-877.

Cosentino, C., R. Paolino, P. Freschi, and A. M. Calluso. 2013. Short communication: Jenny milk as an inhibitor of late blowing in 
cheese: A preliminary report. J. Dairy Sci. 96:3547-3550. https:// doi.org/10.3168/jds.2012-6225.

Cosentino, C., R. Paolino, M. Musto, and P. Freschi. 2015b. Innovative use of jenny milk from sustainable rearing. Pages 113-132 in The Sustainability of Agro-Food and Natural Resource Systems in the Mediterranean Basin. A. Vastola, ed. Springer International Publishing, New York, NY. https://doi.org/10.1007/978-3-319-16357 -4 .

Cosentino, C., R. Paolino, V. Valentini, M. Musto, A. Ricciardi, F. Adduci, C. D'Adamo, G. Pecora, and P. Freschi. 2015a. Effect of jenny milk addition on the inhibition of late blowing in semihard cheese. J. Dairy Sci. 98:5133-5142. https://doi.org/10.3168/jds .2015-9458.

Elshafie, H. S., N. Ghanney, S. M. Mang, A. Ferchichi, and I. Camele. 2016b. An in vitro attempt for controlling severe phytopathogens and human pathogens using essential oils from Mediterranean plants of genus Schinus. J. Med. Food 19:266-273.

Elshafie, H. S., S. Sakr, S. M. Mang, V. De Feo, and I. Camele. 2016a. Antimicrobial activity and chemical composition of three essential oils extracted from Mediterranean aromatic plants. J. Med. Food 19:1096-1103. https://doi.org/10.1089/jmf.2016.0066.

Garde, S., R. Arias, P. Gaya, and M. Nunez. 2011. Occurrence of Clostridium spp. in ovine milk and Manchego cheese with late blowing defect: Identification and characterization of isolates. Int. Dairy J. 21:272-278. https://doi.org/10.1016/j.idairyj.2010.11.003.

Kalač, P. 2011. The effect of silage feeding on some sensory and health attributes of cow's milk: A review. Food Chem. 125:307-317. https: //doi.org/10.1016/j.foodchem.2010.08.077.

Koutb, M., M. Khider, E. H. Ali, and N. A. Hussein. 2016. Antimicrobial activity of donkey milk against dermatomycotic fungi and foodborne bacteria. Int. J. Biomed. Mat. Res. 4:11-17. https://doi .org/10.11648/j.ijbmr.20160403.11.
Labella, C., F. Lelario, S. A. Bufo, M. Musto, P. Freschi, and C. Cosentino. 2016. Optimization and validation of a chromatographic method for quantification of the lysozyme in jenny milk. J. Food Nutr. Res. 55:263-269.

Manchenko, G. P. 1994. Handbook of Detection of Enzymes on Electrophoresis Gels. CRC Press, Boca Raton, FL.

Niro, S., S. Fratianni, G. Colavita, L. Galassi, M. Zanazzi, and E. Salimei. 2017. Technological use of donkey milk in cheese-making. Int. J. Dairy Technol. 70:439-442. https://doi.org/10.1111/1471 -0307.12342 .

Panari, G. S. Perini, R. Guidetti, M. Pecorari, G. Merialdi, and A. Albertini. 2001. Indagine sul comportamento di germi potenzialmente patogeni nella tecnologia del formaggio Parmigiano-Reggiano. Sci. Tecn. Latt. Cas. 52:13-22.

Šarić, L. C., B. M. Šarić, S. Ț. Kravić, D. V. Plavšić, I. Lj. Milovanović, J. M. Gubić, and N. M. Nedeljković. 2014. Antibacterial activity of Domestic Balkan donkey milk toward Listeria monocytogenes and Staphylococcus aureus. Food Feed Res. 41:47-54.

Stadhousers, J., and K. Jørgensen. 1990. Prevention of the contamination of raw milk by a hygienic milk production. Bull. Int. Dairy Fed. 25:132-136.

van Hooijdonk, A. C., K. D. Kussendrager, and J. M. Steijns. 2000. In vivo antimicrobial and antiviral activity of components in bovine milk and colostrum involved in non-specific defence. Br. J. Nutr. 84:S127-S134.

Zhang, X. Y., L. Zhao, L. Jiang, M. L. Dong, and F. Z. Ren. 2008. The antimicrobial activity of donkey milk and its microflora changes during storage. Food Control 19:1191-1195. https://doi.org/10 .1016/j.foodcont.2008.01.005. 